\title{
ENTRE LO DOMÉSTICO Y LO FANTÁSTICO: LAS BRUJAS EN LA NARRATIVA ESPAÑOLA DE TEMA MARROQUÍ1
}

\author{
BETWEEN THE DOMESTIC AND THE FANTASTIC: THE WITCHES \\ IN THE SPANISH NARRATIVE OF MOROCCAN THEME
}

\section{Yasmina ROMERO MORALES}

Universidad de La Laguna

Resumen: El presente trabajo tiene como propósito examinar las estrategias representacionales en torno al personaje de la bruja que han sido halladas en la narrativa española de tema marroquí. Las siguientes páginas repasarán sus imaginados modelos de conducta, el raudal de tópicos repetidos con los que se describe y los valores que se le asignan. Principalmente, se detendrá en sus perfiles más habituales: la curandera, la adivina y la casamentera. En cuanto a las fuentes primarias utilizadas, responden al conjunto de novelas y relatos de ficción escritos por mujeres españolas y que teniendo por tema central Marruecos fueron escritos durante el pasado siglo XX.

Palabras clave: Brujas; narrativa española; mujeres escritoras; estudios de género; Marruecos.

Abstract: The purpose of this paper is to examine the representational strategies around the character of the witch that it has been found in the Spanish narrative of Moroccan theme. The following pages will review their imagined models of conduct, the repeated topics with which they are describes and the values assigned to them. Mainly, it will stop in its most common profiles: the healer, the fortune-teller and matchmaker woman. The primary sources used correspond to the set of novels and fiction stories written by Spanish women and whose central theme was Morocco during the last 20th century.

Keywords: Witches; spanish narrative; women writers; gender studies; Morocco.

\footnotetext{
${ }^{1}$ Este trabajo se ha realizado en el marco del Proyecto de Investigación I+D "Justicia, ciudadanía y vulnerabilidad. Narrativas de la precariedad y enfoques interseccionales" (FFI2015-63895-C2 -1-R) del Ministerio de Ciencias e Innovación.
} 


\section{1}

\section{Introducción}

Hay más de doscientas novelas y relatos de ficción de tema marroquí publicados en España desde mediados del siglo XIX hasta la actualidad. Si además contáramos las obras de no ficción, o de otros géneros literarios como el teatro o la poesía, también los tratados científicos, los manuales militares o desde cualquier otra disciplina, nos daríamos cuenta de que el interés que se ha sentido por Marruecos desde España es especialmente acusado. El motivo principal es la cantidad de acontecimientos históricos que han unido a ambos territorios desde siempre y que tienen su punto más álgido en la implantación del Protectorado Español en Marruecos durante cuarenta y cuatro años, justo hasta la independencia del país en 1956.

Para este trabajo de investigación se ha seleccionado sólo la narrativa de tema marroquí con firma femenina, un conjunto de sesenta y dos ficciones, novelas y relatos, que arrojan un corpus de fuentes primarias compuesto por casi cinco mil páginas. La razón que me llevó a seleccionar sólo a mujeres escritoras fue compensar, de algún modo, el olvido sistemático al que han sido sometidas evidentemente no sólo las autoras de este tema en concreto-y que las ha condenado en la actualidad al olvido, aún a pesar del éxito que algunas de ellas cosecharon en el momento de la publicación de sus textos. Desafortunadamente de muy pocas se recuerda hoy tan sólo su nombre ${ }^{2}$.

Otro interés, además, fue estudiar, desde la perspectiva de género más antiesencialista inspirada en autoras como Judith Butler o Nancy Fraser, la representación de la otredad femenina marroquí en dichas ficciones y, sobre todo, con una nueva mirada en busca, asimismo, de una nueva reinterpretación, como propuso Adrienne Rich en su texto clave Writting as a Re-Vision (1971):

Necesitamos conocer los escritos del pasado y conocerlos en forma distinta a como han sido divulgados hasta ahora, no retransmitir una tradición sino romper las amarras que tienen puestas sobre nosotras. (1983: 48)

Efectivamente, para poder cortar las cuerdas de las representaciones literarias femeninas hegemónicas - ya sean patriarcales y/o occidentales - primero es necesario distinguirlas y comprender, para luego aislarlas y aniquilarlas, «debemos disecar para asesinar» (Gilbert y Gubar, 1998: 32). Y aunque en un primer momento me tuve que rendir a la evidencia de que en la mayoría de las ocasiones la «otra» marroquí participaba del mismo imaginario negativo que su par varón «un ser degenerado, sucio, holgazán, mísero, duro, fanático, ladrón, rastrero, astuto, envidioso, vengativo y orgulloso» (Vázquez Sastre, 1913: 4) ${ }^{3}$. Posteriormente, y tras el análisis pormenorizado de los textos,

\footnotetext{
${ }^{2}$ Las autoras aunadas para este trabajo de investigación son veintidós: Carmen Martel, Concha López Sarasúa, Encarna Cabello, Marisa Villardefrancos, Regina Flavio, Concha Linares-Becerra, Mari Paz Estévez de Castro, Cristina Fernández Cubas, Carmen de Burgos, María Charles, Carmen Martín de la Escalera, María Teresa de Jadraque, María Viñuelas, Blanca Ibáñez Blanco, Josefina María Rívas, Rosa de Aramburu, María Adela Durango, Margarita Astray Reguera, Rosa María Aranda, Julia María Abellanosa, Carmen Nonell y Dora Bacaicoa.

${ }^{3}$ Ese es el retrato del moro que hace el teniente de Infantería Cayetano Vázquez Sastre en una obra que publicó en 1913 bajo el subtítulo de Pequeño estudio psicológico de la raza mora.
} 
se reflejó que, además de tildárselas con los mismos adjetivos negativos de los que se había hecho legatario el moro — así se lo denomina en estas ficciones-, comprendió otros rasgos que resultaban de filtrar todos los anteriores por el tamiz del género.

Vistas así las cosas, pude hallar distintos tipos imaginarios de personajes femeninos marroquíes, de moras, todas ellas representadas por imágenes extremas fuertemente condicionadas por los esquemas culturales y de género de la sociedad de origen de las autoras, por mucho que todas ellas buscaran que sus retratos de la «otra» marroquí pasaran por fidedignos. Hallé en las tramas moras que se confundían con el paisaje por su vestimenta integral; otras a las que se imaginaba provocando tentaciones sexuales puertas adentro de los harenes; algunas más a las que se representaba siempre trabajando en el campo y, finalmente, moras a las que se podría denominar brujas y que se vinculaban con la práctica de ciertas habilidades mágicas como la lectura de cartas o la venta de remedios milagrosos.

Las siguientes páginas repasarán este último personaje femenino, la mora bruja, sus imaginados modelos de conducta, el raudal de tópicos repetidos con los que se describe y los valores que se le asignan.

\section{La mora bruja}

La mora bruja es uno de los personajes femeninos que más aparece en la narrativa española de tema marroquí, su aparición es sistemática en todos y cada uno de los relatos y novelas analizados, pero, también, es el que menos se describe. El retrato de la mora bruja en esta narrativa corresponde a la imagen compartida del imaginario simbólico occidental, aún de plena actualidad, en el que predominan unos pocos rasgos establecidos pero, sin lugar a dudas, suficientes para identificar su figura en la tradición literaria que nos ocupa. Las autoras se valen del bagaje de su público lector conocedor de esa anciana casi siempre desdentada, con atavíos oscuros y rodeada de telarañas y calderos humeantes. Una bruja que se corresponde con la bruja histórica que desde el siglo XIII ha sido condenada a muerte y que no varía de la que aparece en los relatos clásicos del tipo de Blancanieves, Hansel y Gretel o la Bella Durmiente. Son las malas de la historia, lo que Vladimir Propp en la Morfología del cuento (1928) denominó «agresor del protagonista» (2014: 40) y que vienen a «provocar una desgracia, hacer el mal, causar un prejuicio» (2014: 41). Es cierto que la bruja marroquí, la mora bruja, como suele denominársela en las ficciones, no lleva un sombrero alto y puntiagudo ni tiene una escoba con la que puede volar, pero el resto de las características se mantienen intactas, se aleja de las leyes sociales, conoce los secretos de la magia y, también, las propiedades de las plantas que utiliza para preparar brebajes y pociones.

La bruja marroquí permite, además, conectar la narrativa analizada con una ciencia oculta a la que desde la antigüedad se vincula el mundo árabe-islámico: la magia. Las mil y una noches fueron de las primeras fuentes literarias en vincular lo islámico con los genios maravillosos, las ciudades prodigiosas, las brujas y otros elementos y personajes fantásticos. Es lógico, pues, que las autoras que 
quisieron recrear Marruecos durante el pasado siglo XX recurrieran a los elementos sobrenaturales que la propia tradición literaria ha legado y que generan una atracción que siempre ha cautivado a Occidente.

Por otra parte, también es importante señalar que el personaje de la bruja en esta narrativa de tema marroquí no aparece aislado de otros perfiles actanciales que pudiera poseer la otredad femenina marroquí y a los que se hizo brevemente referencia en la introducción de este trabajo. Cualquier mora, por el hecho de serlo, es potencialmente una bruja, dado que nos hallamos en una narrativa donde se busca acentuar los atributos supersticiosos que se presuponen propios del Marruecos imaginado: creencias ancestrales, prácticas hechiceras, supuestos poderes irracionales y distintos ritos como los derivados del fanatismo islámico al que también se le dedican bastantes páginas. Después de todo, como asegura Edris, uno de los protagonistas marroquíes de El sol nace de madrugada (1953): «Sabía que vivía en un pueblo de costumbres primitivas» (Villardefrancos, 1953: 10) así que «[l]as brujerías, más o menos peligrosas, son puestas en juego» (Aramburu, 1937: 135).

Por consiguiente, no sorprende que las familias se acusen unas a otras de brujerías: «No sacarás nada bueno de esa familia, hijo mío; andan en brujerías ... lo han hecho siempre, de veras...» (López Sarasúa, 1988: 106); que cualquier mujer rocíe su casa con fasur, una raíz que se mezcla con azufre y agua y «produce efluvios maravillosos» (López Sarasúa, 2000: 235); que las manos femeninas maquilladas de henna ahuyenten los malos espíritus (López Sarasúa, 1988: 57); que en las puertas de las casas se adviertan «trapos sucios atravesados por alfileres» (López Sarasúa, 1988: 106) o que las vecinas sin hijos echen mal de ojo sobre los niños de aquéllas que sí los tienen (Bacaicoa, 1955: 91). Y es que, en los ojos de toda mujer marroquí se halla «algo del misterio de los gitanos» (Burgos, 1989: 211) y, por tanto, cualquiera es susceptible a ser considerada una bruja, de ahí que se diga de una de ellas a la que observan deambular por su jardín: «Es seguramente algo bruja, apuntó con sorna el muchacho, aludiendo a las creencias de las mujeres marroquíes, y está buscando hierbas para preparar un bebedizo, aunque tal vez esté buscando la hierbabuena para hacer el té» (Martín de la Escalera, 1945: 174-5).

Pongamos otro ejemplo más, el del niño que descubre con muy corta edad que su madre es en realidad una maga:

Una vez que cogió entre sus manos el rostro pensativo de Mamma y miró en sus ojos, quedó asombrado ante el gran secreto. En el azul transparente empezaron a brotar flores, pájaros, lagos de agua pura. Feddul quedó absorto. Nunca había soñado que hubiera algo más lindo que las mariposas de colores maravillosos...

— ¿Por qué me miras así? — preguntó Mamma.

Feddul sonrió misterioso, y no dijo nada porque sabía que era un secreto, pero desde entonces miró a su madre como a una maga. (Bacaicoa, 1955: 37)

En realidad, salvo excepciones, no nos hallamos ante brujas propiamente dichas, aquellas que levitan, vuelan con o sin ayuda de una escoba o se transforman en animales sino frente a mujeres con un saber popular derivado de la tradición o el folclore y cuya magia no es más que una medicina casera que han transmitido de generación en generación. La construcción androcéntrica y misógina de la 
Historia ha querido llamar brujas a estas mujeres que ayudan como comadronas o parteras al parto de otras mujeres, que poseen conocimientos de medicina popular, que saben qué plantas son las más adecuadas según las dolencias y que utilizan el rezado a modo de técnica de sanación. Una vez más salen mal paradas las mujeres en relación a los hombres, que en el «tradicional» reparto de las dotes hechiceras ellos son los brujos intelectuales, estudiosos de pergaminos y pliegos de alto nivel — para ellos siempre ha sido dada la ciencia, recordemos al mago Merlín — y las mujeres, por su parte, serán las de las sonoras carcajadas delante de marmitas humeantes. La tradición judeocristiana ha insistido en la descripción demonizada de la bruja por sus arraigados prejuicios patriarcales y luego esa imagen negativa se ha respaldado con casos, llamémoslos históricos, fuentes judiciales, escritos de tipo demonológico o teológico y dictámenes inquisitoriales. Los textos analizados se enmarcan en esa herencia discursiva, así que es evidente que el personaje de la mora bruja se describa como maligno, dado que hace el trabajo del mismísimo diablo y al que, además, se retrata como un ser de aspecto repulsivo ${ }^{4}$ : «párpados sin pestañas», «boca desdentada» y unos ojos «enrojecidos por los años y las enfermedades más repugnantes» (Martín de la Escalera, 1945: 22).

Mirándolo así, está claro que esta es una representación que no podemos entonces vincular únicamente a la etnia-raza de los personajes femeninos nacidos en Marruecos, no sólo deriva de que estas mujeres recreadas sean identificadas como marroquíes, como moras, sino sobre todo a su género, que sean mujeres. Nunca ha costado demasiado emparentar al género femenino con lo fantástico y con la magia o, al menos, con la superstición y la superchería. De ello resulta, y por poner un único ejemplo, que haya adivinadoras de cartas en este Marruecos imaginado de las que se dice que no son marroquíes, sino centroeuropeas (Nonell, 1956: 161).

Los siguientes apartados se detienen en las representaciones más habituales que de la mora bruja se hace en esta narrativa: la curandera, la adivina y la neqafa o casamentera.

\section{1. La bruja curandera}

Una de las características de este personaje femenino es que suele ser autodidacta. Lo más frecuente es que estas brujas hayan adquirido sus conocimientos a través del examen de la naturaleza, los libros o el estudio de las hierbas. De ahí que la gente acuda a ellas a pedirles favores a pesar del miedo que puedan causar y que, sin duda, ofrezcan una ayuda muy útil a la comunidad. Entre estas brujas destaca la curandera, — «que conocen remedio para todos los males» (Martín de la Escalera, 1945: 27), «remedios contra cualquier dolencia del mundo» (Fernández Cubas, 2009: 7) y «sus palabras transmiten un saber ancestral» (López Sarasúa, 2000: 60) - a la que se acude para que solucione problemas de salud, de amor o de esterilidad. Y, sobre todo, acuden las mujeres porque «todas las moras, [tienen] una gran fe en todas las hechicerías» (Aramburu, 1937: 144).

\footnotetext{
${ }^{4}$ Así lo recoge, asimismo, el Diccionario de la lengua española de la Real Academia en su vigesimotercera edición de 2014, cuya séptima acepción de la entrada bruja es 'Mujer de aspecto repulsivo'.
} 
Una de ellas se representa cabalgando sobre la espalda de una parturienta mientras murmura «extrañas palabras» (Nonell, 1956: 166); otra regala a una de las protagonistas un amuleto del santo Alí — «un ovillo de pingajos atados a una cinta amarilla» (López Sarasúa, 2002: 100)— para ver si dejaba de sangrar por la nariz; y otra más acude a casa de unos españoles cada lunes y viernes porque éstos estaban «hartos de médicos que no aportaban solución alguna» (López Sarasúa, 2000: 176) a su esposa enferma. Esta mora bruja iba derecha a la cocina y se ponía a «majar con paciencia un manojo de albahaca, contra la melancolía y el tormento, afrodisíacos arrayanes, un puñado de comino procedente de Eritrea... Los salmos y conjuros bajaban de su boca al almirez como un fluido» (López Sarasúa, 2000: 176).

Por tanto, se describe como algo natural que los personajes de los textos analizados acudan a los servicios de las curanderas y les compren brebajes que luego usan con sus maridos (Martín de la Escalera, 1945: 105). En las últimas novelas publicadas, incluso, compran pedazos de piel de conejo, púas de puercoespín y piedras perfumadas sin más en los mercados, donde la clientela «se apiña ante el puesto en demanda de remedio para sus males» (López Sarasúa, 2000: 60) y las curanderas «por medio de un micrófono» aconsejan hierbas contra todo tipo de enfermedades, también venéreas. Allí mismo, «de inmediato, puede empezar la cura; las convierte en polvo y las mezcla al té» (López Sarasúa, 2000: 61).

Especial importancia se le da a una mujer «versada en cosas de espíritus y duendes» (Aramburu, 1937: 43) que aparece en la novela Ojos largos (1943) y a la que se denomina «henena». A punto de nacer, una niña dictaminó que la madre tenía «yenún» en el cuerpo y que esa especie de duendecillos estrangularían a la pequeña o «la harían llegar al mundo con las orejas y la nariz retorcidas» (Aramburu, 1937: 43). La «henena» ofrece a la niña al cielo mientras lanza un conjuro y cuelga sobre «un clavo puesto en la cabecera de la colchoneta, la cáscara de un huevo, una cebolla y dos pimientos colorados cuyo olor ya es sabido que repugna a los diablos, y en el vientre de la criatura puso el amuleto máximo, el alfa y omega de todas las conjuraciones, el lied de Fathma, con los cinco dedos tendidos de la mano de la hija del Profeta» (Aramburu, 1937: 45).

En cualquier caso, conforme van pasando las décadas, la labor de la bruja curandera va conquistando cotas de libertad y se la sitúa no sólo en casas y mercados, sino en plena calle. Valga como ejemplo Nawar de ¿Qué buscabais en Marrakech? (2000) que en medio de la Plaza de Yama'a al-Fnaa vende cestos de mimbre, collares ambarinos y «un mare mágnum de quincalla colgada del brazo» (López Sarasúa, 2002: 94).

\section{2. La bruja adivina}

Tras las curanderas, también las adivinas son consideradas un tipo de mora bruja. Unas, por algún tipo de discapacidad, como Zahíra, la ciega que posee el «poder ver lo oculto» (Nonell, 1956: 60) y otras profesionales como Aachuch, de Fatma (1945), una rifeña que echa las cartas, entiende de bebedizos, recetas amatorias y demás brujerías. Su presteza la lleva incluso a tener una consulta donde, 
curiosamente, lee el futuro y adivina el pasado a través de una «ennegrecida baraja española» (Martín de la Escalera, 1945: 23). Sólo España podría hacer que aquellas tierras tuvieran futuro, como colonia: «Tu camino es blanco y negro... Blanco por la derecha, negro por la izquierda, por el corazón. Pero tu estrella es favorable, luce, reluce y no se apaga, y es de oro y plata. No has sido nunca pobre, ni lo eres, ni lo serás con la ayuda de Dios, dispensador de las riquezas» (Martín de la Escalera, 1945: 25).

Por la boca de la mora bruja salen torrentes de revelaciones «enrevesadas, poéticos y absurdos conceptos, vagas indicaciones que parecían reflejar visiones de cuentos y sueños» (Martín de la Escalera, 1945: 25) y «conjuros de amor o de muerte» (López Sarasúa, 2000: 61). Por otro lado, también las adivinas ejercen su trabajo por las calles marroquíes, instando a los turistas a saber su porvenir en las «líneas de la mano» a cambio de unos cuantos dírhams (López Sarasúa, 2002: 95).

\section{3. La bruja casamentera}

La literatura española sabe mucho de casamenteras, llegó incluso a dedicarle una de sus obras cumbres, La Celestina (1499) de Fernando de Rojas, que convirtió en inmortal definitivamente a este arquetipo femenino. Por tanto, es muy frecuente hallar por las páginas de la narrativa patria a las casamenteras oficiando de intermediarias entre las parejas, tratando de conseguir que se conozcan, que congenien y surja la unión con fines matrimoniales. A cambio, ella saca provecho económico.

Estudiar la dimensión de la casamentera desde una perspectiva de género nos devuelve la realidad de su necesidad, sobre todo en la antigüedad, cuando una mujer no podía intentar por ella misma conseguir marido y requería los servicios de las casamenteras tal que si fuera un médico o un letrado. En una sociedad de contexto árabe-islámico como Marruecos a la que se imagina impidiendo la libre circulación de las mujeres, donde se insiste en su enclaustramiento y que son casi reclusas en sus propias casas, aún es más lógico que se recurriera a ellas. Las casamenteras acuden a las casas con la excusa de actividades inocentes, como vender joyas, remedios o cosméticos. Sin embargo, este tipo de bruja es denigrada y menospreciada en la narrativa analizada, incluso por quienes utilizan sus servicios, de ahí que se advierta que hay que desconfiar «de esas mujeres como el diablo» (Nonell, 1956: 26).

\section{A modo de conclusión}

El personaje de la mora bruja al que se le da tan poco pábulo en el género sometido a estudio es, tal vez, el único con verdaderos visos de agencia que posee la otredad femenina marroquí de la narrativa analizada. En un primer lugar, porque la magia es ya de por sí, un elemento de subversión, que se enfrenta al orden racional. Pero, también, porque en todas estas narrativas el peso del islam es fundamental y se asegura incluso en alguna de las ficciones que estas prácticas estaban prohibidas por la religión islámica (Martín de la Escalera, 1945: 115). Esto es, la mora bruja no respeta las normas de su comunidad pero tampoco las de la comunidad que la observa en la medida que, tanto una como otra, son patriarcales y abogan por una mujer sin señal alguna de empoderamiento. De ahí, que se le 
dé poco espacio en esta narrativa orientalista en la que las mujeres marroquíes no son especialmente bien tratadas y, de ser posible, incluso se la castigue por transgredir los límites del canon, como al personaje de Malica del relato «Una vida» incluido en Fatma (1945) al que detienen por hacer brujería y le dan cien palos para que confiese (Martín de la Escalera, 1945: 116).

Lo que está claro es que el principal miedo que se vislumbra en esta bruja marroquí es no ceñirse a la opresión normalizadora del orientalismo — que también es patriarcal— por lo que se revela la fragilidad y relatividad del propio sistema de dominación, como así lo han advertido, entre otros, René Girard (1986: 33). De los personajes marroquíes habituales y hallados en las ficciones analizadas, sólo la mora bruja causa desconfianza. Se la considera una amenaza porque es una mujer fuerte y autónoma que transgrede las normas de su género y que resignifica los símbolos de su servidumbre doméstica como los calderos y almireces a los que convierte en canales de libertad. Su tradicional reclusión en el espacio doméstico y las tareas del hogar se vuelven, de este modo, en una fuente de poder.

La mora bruja bien sería uno de estos personaje-tipo que, aun rechazados por la tradición, la crítica literaria feminista podría decidir rescatar, en la línea de los trabajos de Barbara Walker, Emma Donoghue o Marina Warner que ilustran los esfuerzos de reescritura desde un enfoque de género, sobre todo de los cuentos de hadas clásicos legados por la tradición. Es indudable que la madrastra, la hermanastra, el hada malvada o las brujas son prototipos femeninos que han demostrado con su existencia literaria que su autonomía no depende de ningún hombre, ni de su belleza, ni de su pasividad. Son inteligentes, independientes, se lucran de ello y, por tanto, se encuentran más acordes con las propuestas subversivas de los postulados feministas. Luego, por eso, su presencia es constante pero tangencial en la narrativa española de tema marroquí analizada.

\section{Bibliografía}

Abellanosa, J. M. de (1944): Y llegó el plenilunio. Madrid, Gráficas Reunidas.

ARAMBURU, R. de (1937): Ojos largos. Madrid, Editorial Española.

ARANDA, R. M. (1945): Tebib. Zaragoza, Artes Gráficas E. Bermejo Casañal.

AstRa y Reguera, M. (1925): «Pasión de moro», Los contemporáneos, 879.

BACAICOA, D. (1955): Zohora la negra y otros cuentos. Tetuán, Manantial.

BURGOS, C. de (1989): «En la guerra», en Concepción NúÑEZ REY, ed., La flor de la playa y otras novelas cortas. Madrid, Castalia, pp. 163-218.

CABELlO, E. (1994): «Un fugaz aire sahariano», en VV. AA, Relatos de mujeres viajeras. Barcelona, Sua, pp. 225-230.

- (1995): La cazadora. Melilla, Textos Mediterráneos.

(1999): El cenicero. Granada, Universidad de Granada.

(2000): Alizmur. Barcelona, Meteora.

CHARLES, M. (1993): Etxezarra. Barcelona, Anagrama.

Donoghue, E. (1995): Kissing the Witch: Old tales in New Skins. New York, Harper Collins. 
Entre lo doméstico y lo fantástico: las brujas en la narrativa española de tema marroquí

Durango, M. A. (1943): Ojos verdes. Madrid, Pueyo.

EstÉvez de CASTRO, M. P. (1954): El convoy de la muerte. Madrid, Pueyo.

FERNÁNDEZ CuBAS, C. (2009): El vendedor de sombras. Barcelona, Alfabia.

Flavio, R. (1938?): Alma de Marruecos. Barcelona-Sevilla, Betis.

GILBER, S. M. - GUBAR, S. (1998): La loca del desván. La escritora y la imaginación literaria del siglo XIX. Madrid, Cátedra.

GIRARD, R. (1986): El chivo expiatorio. Barcelona, Anagrama.

IBÁÑEZ BlAnCO, B. (1956): Noche nupcial sin novia. Granada, B. I. B. Imprenta José María Ventura Hita.

JADRAQUe, M. T. de (1954): Halima. Madrid-Cádiz, Escelicer.

LinARES-BeCERrA, C. (1962): Cita en el paraíso. Madrid, C. L. B. Imprenta Sáez. (1971): Muchachas sin besos. Madrid, Cunillera.

LÓPEZ SARASÚA, C. (1988): A vuelo de pájaro sobre Marruecos. Alicante, Cálamo.

- (2000): La llamada del almuédano. Alicante, Cálamo.

- (2002): ¿Qué buscabais en Marrakech? Alicante, Cálamo.

MARTEL, C. (1956): ¡Demasiado tarde! Madrid, Pueyo.

MARtín DE LA EsCALERA, C. (1945): Fatma. Cuentos de mujeres marroquíes. Madrid, Publicaciones África-Instituto de Estudios Políticos.

Nonell, C. (1956): Zoco grande. Madrid, Colenda.

Prope, V. (2014): Morfología del cuento. Madrid, Akal.

Rich, A. (1983): «Cuando las muertas despertamos: escribir como re-visión (1971)», en Sobre mentiras, secretos y silencios. Barcelona, Icaria, pp. 45-67.

RIVAS, J. (1949): Noches de Tánger. Barcelona, Bruguera.

VÁzQuez SASTRE, C. (1913): En tierras del Rif. Pequeño estudio psicológico de la raza mora. Melilla, Imprenta La Africana.

VillaRdeFRANCOS, M. (1953): El sol nace de madrugada. Madrid, Biblioteca de Chicas.

- (1956): Alma. Madrid, Biblioteca de Chicas.

VIÑUELAS, M. (1946): Los vencidos. Madrid, Aguilar

WALKER, B. (1997): Feminist Fairy Tales. New York, Harper Collins.

WARnER, M. (1995): From the Beast to the Blonde: On fairy Tales and Their Tellers. London, Vintage. 